\title{
Socioeconomic position and risk of atrial fibrillation: a nationwide Danish cohort study
}

\author{
Elin Danielsen Lunde (D) , ',2,3 Albert Marni Joensen, ${ }^{1}$ Søren Lundbye-Christensen, 2,4 \\ Kirsten Fonager, ${ }^{5,6}$ Søren Paaske Johnsen, ${ }^{7}$ Mogens Lytken Larsen, 1,3 \\ Martin Berg Johansen, ${ }^{4}$ Sam Riahi ${ }^{1,2,6}$
}

\begin{abstract}
- Additional material is published online only. To view please visit the journal online (http://dx.doi.org/10.1136/ jech-2019-212720).
\end{abstract}

'Department of Cardiology, Aalborg University Hospital, Aalborg, Denmark

${ }^{2}$ Aalborg AF Study Group, Aalborg University Hospital, Aalborg, Denmark ${ }^{3}$ Danish Centre against Inequality in Health (DACUS), Department of Cardiology, Aalborg University Hospital, Aalborg, Denmark

${ }^{4}$ Unit of Clinical Biostatistics, Aalborg University Hospital, Aalborg, Denmark

${ }^{5}$ Department of Social Medicine, Aalborg University Hospital,

Aalborg, Denmark

${ }^{6}$ Department of Clinical Medicine, Aalborg University, Aalborg, Denmark Danish Center for Clinical Health Services Research, Department of Clinical Medicine, Aalborg University, Aalborg, Denmark

\section{Correspondence to} Dr Elin Danielsen Lunde, Department of Cardiology, Aalborg University Hospital, Aalborg 9000, Denmark; e.lunde@rn.dk

Received 28 May 2019 Revised 28 August 2019 Accepted 16 September 2019 Published Online First 16 October 2019

\section{Check for updates}

(c) Author(s) (or their employer(s)) 2020. No commercial re-use. See rights and permissions. Published by BMJ.

To cite: Lunde ED, Joensen AM,

Lundbye-Christensen S, et al. $J$ Epidemiol Community Health 2020:74:7-13.

\section{ABSTRACT}

Aim To examine the association between

socioeconomic position and the risk of atrial fibrillation (AF) in different stages of life in a population of Danish citizens.

Methods Register-based study. We followed all individuals turning 35, 50,65 or 80 years from 1 January 1996 to 31 December 2005 until AF, death, emigration or the end of study period (31 December 2015). Exposure was education and income. We used Cox regression for the HRs $(95 \% \mathrm{Cl})$ and the pseudo-observation method for the adjusted risk difference (RD) (\%).

Results A total of 2173857 participants were enrolled and 151340 incident cases of AF occurred over a median of 13.6 years of follow-up. Adjusted HR (95\% $\mathrm{Cl}$ ) of incident $\mathrm{AF}$ for the youngest age group with the highest education (ref lowest) was 0.62 (0.50 to 0.77 ) (women) and 0.85 (0.76 to 0.96 ) (men). The associations attenuated with increasing age, that is, HRs for the oldest age group were 1.04 (0.97 to 1.10) and 0.98 (0.96 to 1.04), respectively. The corresponding adjusted RDs (\%) were: $-0.28(-0.43$ to -0.14$),-0.18(-0.36$ to -0.01$), 3.04(-0.55$ to 6.64$)$ and -0.74 ( -3.38 to 2.49), respectively. Similar but weaker associations were found for income.

Conclusion Higher level of education and income was associated with a lower risk of being diagnosed with AF in young individuals but the association decreased with increasing age and was almost absent for the oldest age cohort. However, since AF is relatively rare in the youngest the RDs were low.

\section{BACKGROUND}

Atrial fibrillation (AF) is the most common cardiac arrhythmia worldwide and it is a considerable source of mortality and morbidity such as stroke and congestive heart failure. ${ }^{12} \mathrm{AF}$ is currently estimated to affect approximately $2 \%$ of the world population and the prevalence is progressively increasing, making $\mathrm{AF}$ a rising global health burden. ${ }^{3}$

Several studies have demonstrated that low socioeconomic position (SEP) is associated with a higher risk of cardiovascular diseases (CVD) such as stroke and ischaemic heart disease. ${ }^{45}$ One might expect the same pattern between SEP and AF, as AF shares many of the traditional cardiovascular risk factors such as obesity, hypertension or diabetes. However, only approximately $50 \%$ of AF cases are estimated to be explained on the basis of these risk factors, and the remaining causes are unknown or suggested to be, for example, alterations in the autonomic nervous system or genetics. ${ }^{6}$ The latter might especially be the case for younger adults with 'lone AF'. Accordingly, previous studies show inconsistent results which have varied with country of origin and different indicators of SEP. ${ }^{8}$ For example, one of the studies indicates that, for example, low education increases the risk of $\mathrm{AF}^{9}{ }^{9}$ while other studies indicate that deprivation and high income increase the risk of $\mathrm{AF}^{10}{ }^{11}$ None of the previous studies have stratified the results according to age, which otherwise could be of great importance, as the aetiology and mechanisms behind AF probably differ for younger and older adults. ${ }^{12}$ Furthermore, although different indicators of SEP, such as income and education, are strongly correlated, they should not be used interchangeably as different indicators may give different results. ${ }^{13}$ Consequently, it remains poorly understood if SEP is associated with the risk of being diagnosed with $\mathrm{AF}$ and the possible public health impact it may have.

The aim of this study was to examine the association between SEP, for example, education and income, and the risk of a hospital diagnosis of $\mathrm{AF}$ in different ages in the Danish population. We hypothesised that short education and low income were associated with higher risk of being diagnosed with $\mathrm{AF}$ and that the associations might be stronger for younger adults.

\section{METHODS}

\section{Study design and data sources}

This was a register-based observational cohort study using nationwide registers from Statistics Denmark. We used the following five Danish registers: (1) The Danish National Patient Register, which holds information on procedures and diagnoses from hospitals since 1977. The diagnoses were coded using the International Classification of Diseases Eighth Revision (ICD-8) before 1994, and from January 1994 ICD-10. ${ }^{14}{ }^{15}$ (2) The National Prescription Registry, which uses the Anatomical Therapeutic Chemical (ATC) Classification System and holds information on all dispensed prescriptions from Danish pharmacies since 1994. ${ }^{16}$ (3) The Income Statistics Registry, which holds information about household income since $1970 .{ }^{17}$ (4) The Population Education Registers, which holds information on level of education and contains information since $1910 .{ }^{18}$ (5) The Danish Civil Registration System, which includes demographic information such as age, sex, cohabiting status, citizenship and municipality of 

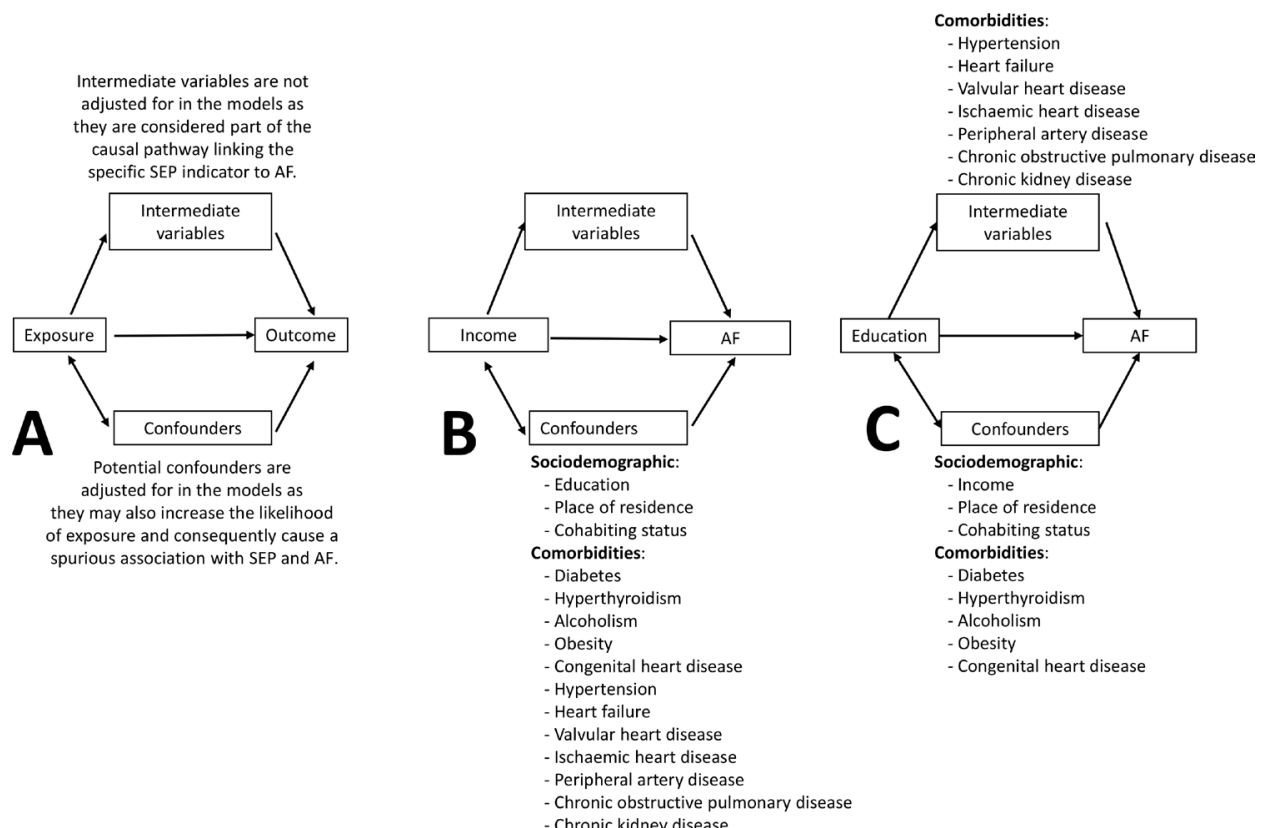

Sociodemographic:

- Income

Place of residence

- Cohabiting status

Comorbidities:

Hyperthyroidism

Alcoholism

- Obesity

Congenital heart disease

Figure $1 \mathrm{AF}$, atrial fibrillation; SEP, socioeconomic position. (A) shows how covariates were considered as either intermediate variables or confounders. Only confounders were adjusted for in the analysis. We did not adjust for the same confounders in income and education, as it is unlikely that education is affected by traditional risk factors for AF such as myocardial infarction and heart failure as education is established early. Consequently, when studying education as the exposure, we did not consider these risk factors as confounders but instead as intermediate variables as part of the causal pathway between education and AF. (B) shows the covariates that were considered as confounders for income. (C) shows the covariates that were considered as confounders or intermediate variables for education. Please see Supplementary material "Tables and supplementary S6" for further justification for choice of confounders.

residence since 1960. Furthermore, all Danish citizens have a unique 10-digit Civil Personal Register number which enables linkage between all the national registers. ${ }^{19}$

\section{Settings, study population and follow-up}

All Danish citizens in the age 35,50,65 or 80 years old between 1 January 1996 and 31 December 2005 were identified in Danish registers. By stratifying the analysis into different age cohorts, it allowed us to collect exposure (education and income) at the same point in life, as income and education are strongly age and period dependent. ${ }^{13}$ Furthermore, age is a strong risk factor for $\mathrm{AF}$ and the underlying pathophysiological mechanisms may differ in young and old adults. ${ }^{12}$ We excluded all individuals with an AF diagnosis registered prior to date of inclusion (back to 1986) or missing information about exposure (education or income). Each individual was considered at risk for AF from the day they turned 35, 50, 65 or 80 years between 1 January 1996 and 31 December 2005 until a diagnosis of AF, death, emigration or the end of the study period (31 December 2015).

\section{Education and income}

As we wanted to assess the association with AF, information about SEP was obtained at the respective date of inclusion (ie, at age $35,50,65$ or 80 years old). Household income was the equivalised household income and drawn from the Income Statistics Register. ${ }^{17}$ To reduce the impact of inflation and to take changes over calendar time in salaries into account, we used age and calendar year-specific tertiles of baseline income. The tertiles were split every 2.5 years as annual inflation in Denmark is generally low $(<2 \%)$ and constant. Information about the highest completed level of education for each participant was obtained from the Population Education Register. ${ }^{18}$ We divided the level of education into age-specific groups (low, medium and high) based on the distribution of education in each age cohort (online supplementary material, tables 1-3).

\section{Diagnosis of $\mathrm{AF}$ and/or atrial flutter}

Information on AF hospital diagnosis was obtained from The Danish National Patient Register. All contacts, including hospital admissions and outpatient visits (but not emergency department visits) with a primary or secondary diagnosis were included. We defined the outcome of this study as AF using the combined ICD-10 code for AF and/or atrial flutter (I48). This is in accordance with previous epidemiological studies ${ }^{20}$ and the validity of the combined diagnosis is high. ${ }^{21}$ Hence, the combined diagnosis of $\mathrm{AF}$ and/or atrial flutter is referred to as 'AF'.

\section{Covariates}

AF-related comorbidities were defined as a combination of diagnoses and prescriptions and the specific ICD and ATC codes used are available in online supplementary material, table 4 . Information about redeemed prescriptions was obtained from the National Prescription Registry. ${ }^{16}$ Information about age, sex, place of residence and cohabiting status was drawn from The Danish Civil Registration System. ${ }^{19}$ Place of residence was grouped according to type of municipality into peripheral, rural, suburban/intermediate and urban municipalities (online supplementary material, table 5$)^{22}$ and cohabiting status was divided into 'living alone' or 'living together with one or more persons'.

\section{Statistics}

Baseline characteristics at the specific age of study inclusion were described for each age cohort using percentages. In analyses comparing incidence rates of AF between different exposure groups, we used Cox regression with age as timescale to estimate 
Table 1 Baseline characteristics for individuals aged 35, 50, 65 or 80 years between 1996 and 2006

\begin{tabular}{|c|c|c|c|c|}
\hline Baseline age & 35 years & 50 years & 65 years & 80 years \\
\hline Overall, n (\%) & $729989(33.5)$ & 720398 (33.1) & 467649 (21.5) & $255821(11.7)$ \\
\hline Events AF, n (\%) & $6590(0.9)$ & $31363(4.3)$ & $63221(13.4)$ & $50166(19.6)$ \\
\hline Male, n (\%) & $369417(50.6)$ & 362399 (50.1) & $224983(48.1)$ & 99089 (38.7) \\
\hline Women, n (\%) & 360572 (49.4) & 357999 (49.7) & $242666(51.9)$ & $156732(61.3)$ \\
\hline \multicolumn{5}{|l|}{ Education, n (\%) } \\
\hline Lowest & $227085(31.11)$ & 239368 (33.2) & $236526(50.5)$ & $123511(48.3)$ \\
\hline Middle & 437484 (59.9) & 433607 (60.2) & $170286(36.4)$ & $119670(46.8)$ \\
\hline Highest & 65420 (8.9) & $47423(6.6)$ & $60837(13.0)$ & $12603(4.9)$ \\
\hline \multicolumn{5}{|c|}{ Household income, tertiles (\%) } \\
\hline Lowest & $243331(33.3)$ & 240137 (33.3) & $155884(33.3)$ & $85276(33.3)$ \\
\hline Middle & $243333(33.3)$ & 240132 (33.3) & $155883(33.3)$ & $85273(33.3)$ \\
\hline Highest & $243325(33.3)$ & 240129 (33.3) & 155882 (33.3) & $85272(33.3)$ \\
\hline \multicolumn{5}{|l|}{ Place of residence (\%) } \\
\hline Peripheral & $61423(8.5)$ & $70542(9.8)$ & $49472(10.6)$ & $28571(11.2)$ \\
\hline Rural & $195267(26.9)$ & $210401(29.3)$ & $140917(30.29)$ & $74286(29.1)$ \\
\hline Intermediate & $108588(14.9)$ & $114202(15.9)$ & $71021(15.2)$ & $37620(14.7)$ \\
\hline Urban & 360992 (49.7) & $320878(44.8)$ & $203848(43.8)$ & $114337(44.9)$ \\
\hline \multicolumn{5}{|l|}{ Cohabiting status } \\
\hline Living alone & $138013(18.9)$ & 141959 (19.7) & $122242(26.14)$ & $118384(46.28)$ \\
\hline Not living alone & $591974(81.09)$ & $578432(80.29)$ & 345389 (73.86) & $137400(53.7)$ \\
\hline \multicolumn{5}{|l|}{ Comorbidity, n (\%) } \\
\hline Hypertension & $6862(0.9)$ & $44822(6.2)$ & $78362(16.7)$ & $66592(26.0)$ \\
\hline Heart failure & $110(0.0)$ & $905(0.1)$ & $4218(0.9)$ & 8767 (3.4) \\
\hline $\begin{array}{l}\text { Valvular heart } \\
\text { diseases }\end{array}$ & $626(0.1)$ & $1380(0.2)$ & $3085(0.6)$ & $4214(1.6)$ \\
\hline $\begin{array}{l}\text { Ischaemic heart } \\
\text { diseases }\end{array}$ & $1680(0.2)$ & $15101(2.10)$ & 34269 (7.3) & 29683 (11.6) \\
\hline $\begin{array}{l}\text { Peripheral artery } \\
\text { disease }\end{array}$ & $368(0.0)$ & $2603(0.3)$ & $9155(1.9)$ & $9751(3.8)$ \\
\hline $\begin{array}{l}\text { Congenital heart } \\
\text { disease }\end{array}$ & $606(0.0)$ & $319(0.0)$ & $180(0.0)$ & $59(0.0)$ \\
\hline Stroke & $1450(0.2)$ & $5496(0.7)$ & 12255 (2.6) & 15239 (5.9) \\
\hline COPD & $1144(0.16)$ & $5635(0.7)$ & 14655 (3.13) & 14114 (5.5) \\
\hline Renal disease & $2341(0.32)$ & $2884(0.4)$ & $3506(0.75)$ & $2971(1.16)$ \\
\hline Alcoholism & $8356(1.1)$ & $15401(2.1)$ & 8197 (1.75) & $2074(0.81)$ \\
\hline Obesity & $5284(0.7)$ & $5908(0.8)$ & $4904(1.0)$ & $1933(0.7)$ \\
\hline Diabetes mellitus & $6306(0.8)$ & $15730(2.1)$ & 24944 (5.3) & 17769 (6.9) \\
\hline Hyperthyroidism & $3066(0.4)$ & $5434(0.7)$ & $6000(1.2)$ & $5756(2.2)$ \\
\hline
\end{tabular}

$\mathrm{AF}$, atrial fibrillation; $C O P D$, chronic obstructive pulmonary disease

cause-specific hazard rate ratios (HR) and 95\% CI in the same four age cohorts. We supplied with absolute risks and risk differences (RD) with 95\% CIs for incidence of AF during follow-up by means of the pseudo-observation method. The pseudoobservation method produces individual risk estimates for $\mathrm{AF}$ in a given time frame. In a competing risk setting as in the present study, these estimates are based on the Aalen-Johansen estimator of the cumulative incidence function and a leave-one-out technique. The important property is that it is possible to perform regression analysis to estimate associations between risk factors and the risk of $\mathrm{AF}^{23}$

The AF risk was calculated for four 15 -year periods (35-50, $50-65,65-80$ and $80-95$ years). Both crude and adjusted RDs and HRs were calculated. All analyses were sex stratified and death was considered as a competing risk when calculating pseudo-observations.

We defined all potential confounding factors a priori and adjusted for them in different models. Model 1 was the crude model, model 2 was adjusted for sociodemographic confounders and model 3 for comorbidities. Choice of confounders for the models is explained in figure 1 and online supplementary material, tables and S6.

For the pseudo-observation method we checked the assumptions of strongly independent entry and censoring and that the distribution of censoring time was independent of covariates. ${ }^{24}$ For the Cox regression, we investigated the assumption of proportional hazard by visual inspection of scatter plots of scaled Schoenfeld residuals versus event times. We used Stata statistical software (V.15; StataCorp) for the statistical analysis.

\section{RESULTS \\ Study population and baseline characteristic}

We identified 2463135 individuals with the age 35, 50, 65 or 80 during the period 1 January 1996 to 31 December 2005. Of those, 33451 with $\mathrm{AF}$ at baseline and 255827 with missing information about income were excluded $(10.5 \%$ of the eligible population) (online supplementary material, table S7), leaving a study population of 2173857 individuals divided into four age cohorts as shown in the flow chart (online supplementary material figure S1). Baseline characteristics and the final distribution of education according to baseline age are presented in table 1. The median follow-up was 13.6 years.

\section{Education}

Fully adjusted HRs and RDs with 95\% CI for AF are shown in figures 2 and 3, while the crude results are available in supplementary material S8 and S9. Men with the highest education had a statistically lower HR of AF compared with the lowest education but the association was attenuated with age (crude HR and $95 \%$ CI for 35, 50, 65 and 80 years old: 0.84 (0.75 to 0.93 ), 0.88 (0.83 to 0.93 ), 0.94 (0.91 to 0.97 ) and 0.98 (0.93 to 1.04 ), respectively).

Women with the highest education had statistically lower HR of $\mathrm{AF}$ but the association was attenuated with age (crude HR and $95 \% \mathrm{CI}$ for $35,50,65$ and 80 years old: 0.57 (0.46 to 0.70$)$, 0.77 (0.69 to 0.85$), 0.85$ (0.82 to 0.88 ) and 1.01 (0.95 to 1.07), respectively). The estimates remained similar but were slightly attenuated after adjustment for other sociodemographic factors and comorbidity. Figure 3 shows the adjusted RDs.

\section{Household income}

In the crude analysis (model 1), men with the highest income and the ages 50 and 65 at baseline had a statistically lower HR of AF than those with the lowest income (HR $=0.91$ (95\% CI 0.88 to 0.94 ) and 0.91 (95\% CI 0.89 to 0.94$)$, respectively). The estimates were attenuated after stepwise adjustment for other sociodemographic factors and comorbidities (online supplementary table S8 and figure 2). However, the youngest men with medium income had a higher risk of AF compared with men with the lowest income, especially after adjusting for both sociodemographic factors and comorbidity (model $3 \mathrm{a})(\mathrm{HR}=1.12$ (95\% CI 1.04 to 1.20$)$ ).

Women with the highest income had a statistically lower HR of AF compared with women with the lowest income, and the association was attenuated with increasing age (crude HR and 95\% CI for 35, 50, 65 and 80 years old, respectively: $0.83(0.75$ to 0.93 ), 0.75 ( 0.71 to 0.78 ), 0.83 (0.81 to 0.86 ) and 0.93 (0.91 to 0.96$)$ ). The RDs show the same trend as HRs, but the association was smaller in the young age cohorts due to lower incidence rates of $\mathrm{AF}$. 


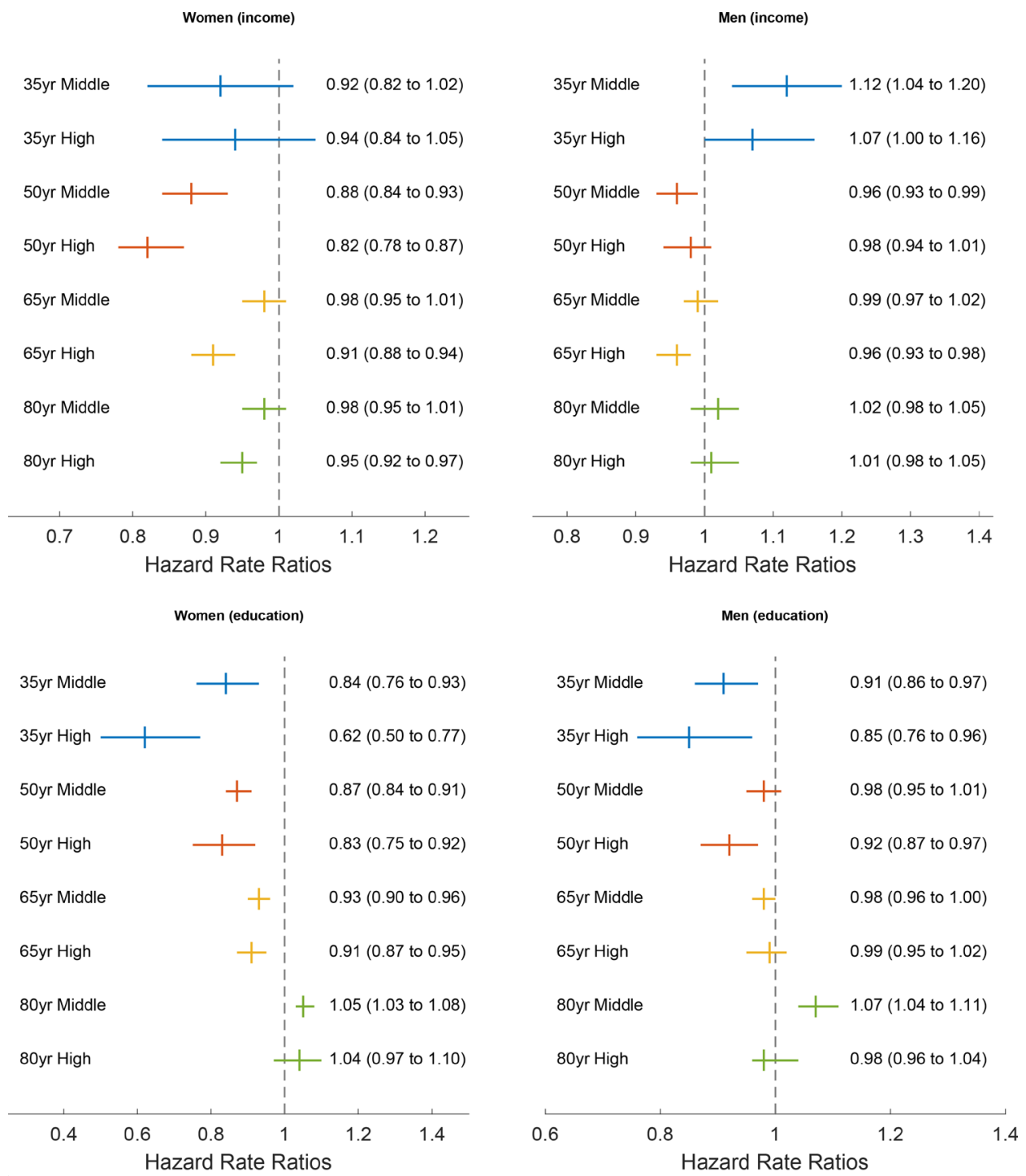

Figure $2 \mathrm{Yr}$, years. Adjusted Hazard rate ratios for AF by income and education stratified by sex. Reference is 1 (lowest tertile for income and lowest educational group).The results are adjusted for model 2 and 3a/3b: Model 2 and 3a (income): Adjusted for income/education, place of residence, cohabiting status, hypertension, heart failure, valvular heart disease, diabetes mellitus 1 and 2, ischemic heart disease, peripheral artery disease, hyperthyroidism, chronic obstructive pulmonary disease, chronic kidney disease, alcoholism, obesity and congenital heart disease. Model 2 and $3 \mathrm{~b}$ (education): Adjusted for income/education, place of residence, cohabiting status, diabetes mellitus 1 and 2, hyperthyroidism, alcoholism, obesity and congenital heart disease.

\section{DISCUSSION}

In this cohort study, we found that higher education was associated with lower risk of $\mathrm{AF}$ in men and women, and that the association persisted after adjusting for confounders. However, the association attenuated with increasing age (65 and 80 years) and the association was even reversed for the oldest age cohort. Young and middle-aged women with high household income had a lower risk of AF but the association decreased with increasing age. Young men with high and middle income had a slightly higher risk of AF than those with the lowest income, while there was no significant difference for men aged 50, 65 or 80 . As the prevalence of AF is low in the youngest adults, the associations were negligible or non-significant in absolute numbers as reflected by the low RDs. The largest RD was observed for women with low income and education in the age of 65 years.

The causal pathway linking SEP to AF has not been thoroughly investigated and it may differ for education and income (see figure 4). There is no obvious direct biological mechanism for the observed association between low education and higher risk of AF. ${ }^{92-27}$ However, the association may be explained by intermediate variables. There is a strong association between low education and higher risk of several AF risk factors such as ischaemic heart disease and hypertension. ${ }^{525} 28$ Education is usually established early in life and it is unlikely that other AF risk factors influence choice or establishment of education. Hence, other AF risk factors may be the causal pathway linking education to AF.

We observed that young men with middle income had higher risk of AF compared with young men with low income, which is partly supported by previous studies. ${ }^{10} 11$ Contrary to education, income is a more unstable measure, which changes over time. Additionally, the association with AF risk factors may be directional, for example, although low income is associated with increased risk of myocardial infarction, myocardial infarction may also cause sick leave, unemployment and herein lower income. Consequently, AF risk factors may act as confounders in the relationship with income and not necessarily as part of 

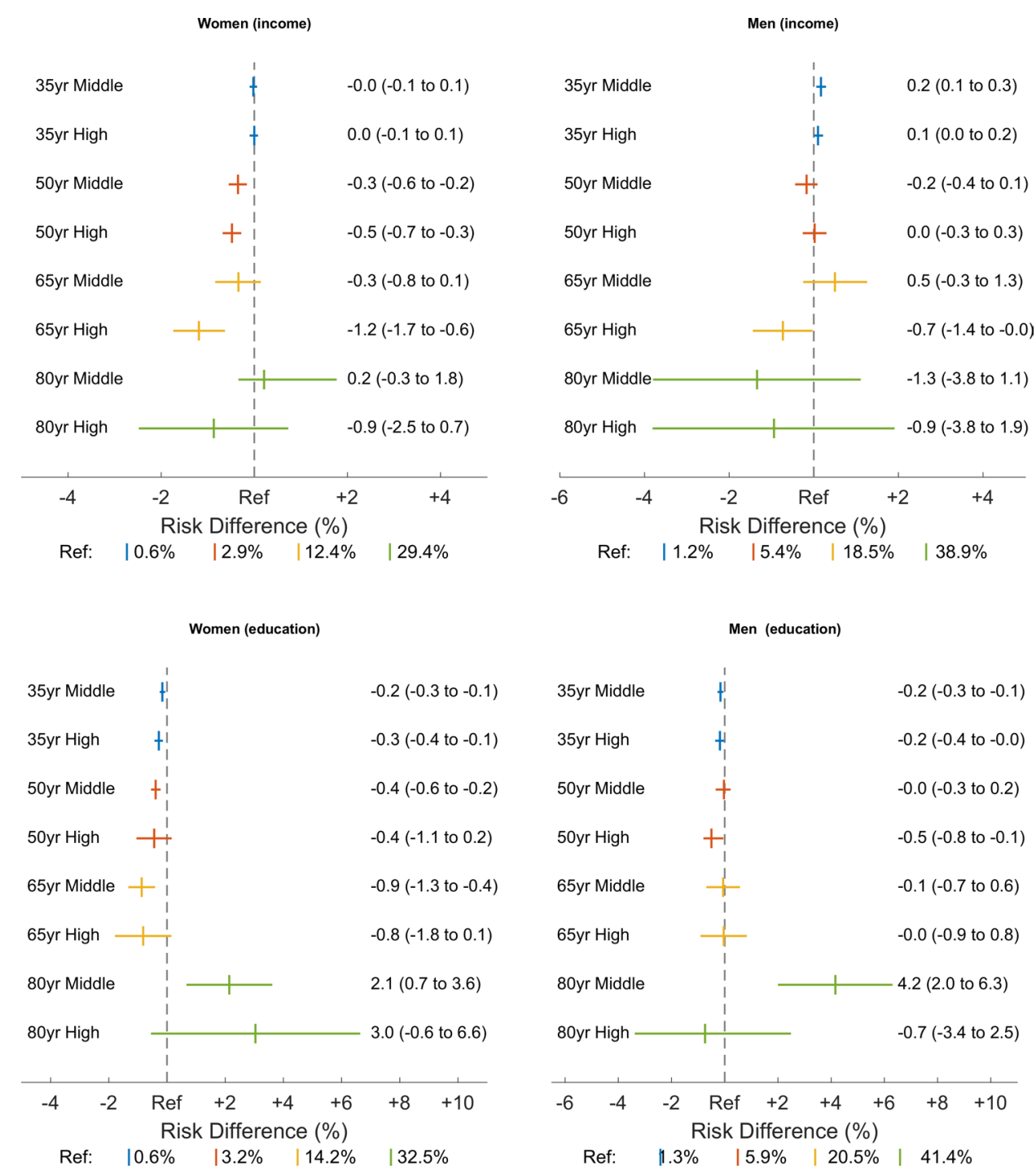

Figure3 $\mathrm{Yr}$, years. Adjusted risk difference of AF by income and education stratified by sex. Reference (Ref.) is the absolute adjusted risk of AF for individuals with the lowest education/income. The results are adjusted for model 2 and 3a/3b: Model 2 and 3a (income): Adjusted for income/ education, place of residence, cohabiting status, hypertension, heart failure, valvular heart disease, diabetes mellitus 1 and 2 , ischemic heart disease, peripheral artery disease, hyperthyroidism, chronic obstructive pulmonary disease, chronic kidney disease, alcoholism, obesity and congenital heart disease. Model 2 and $3 \mathrm{~b}$ (education): Adjusted for income/education, place of residence, cohabiting status, diabetes mellitus 1 and 2, hyperthyroidism, alcoholism, obesity and congenital heart disease.

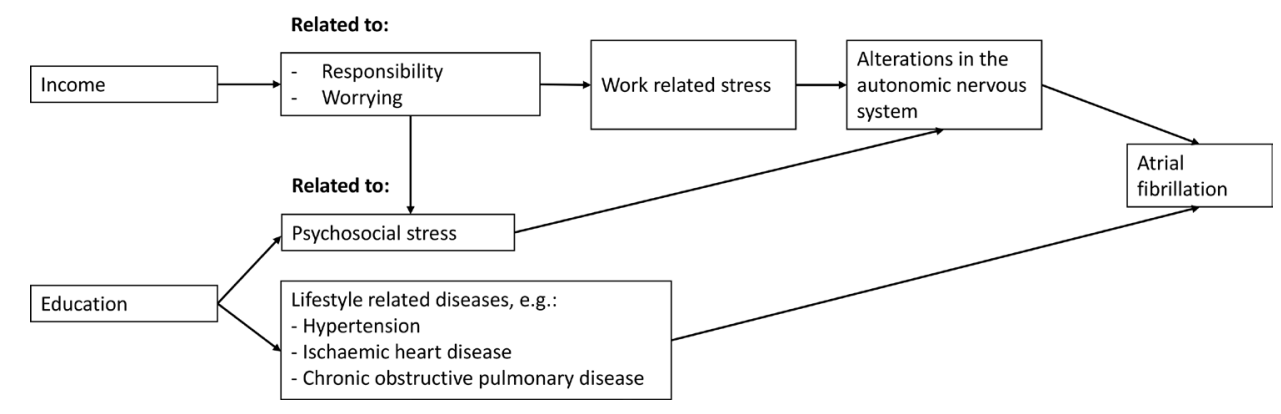

Figure 4 The diagram illustrates the hypothesized pathways for how income and education are linked to AF. Both very high and very low income may produce stress. For example, low income may cause stress and worrying about paying bills and the future, while high income is often associated with stressful jobs with responsibility, expectations and pressure. Low education is associated with life style related diseases which may also be AF risk factors. 
the causal pathway. However, a biological mechanism linking income to stress and subsequent $\mathrm{AF}$ is possible (eg, alterations in the autonomous nervous system). ${ }^{29}$ Individuals with highincome jobs may experience more pressure and stress both at home and in the work environment. ${ }^{30}$ Existing literature has indicated that men with work-related stress have a higher risk of $\mathrm{AF}^{2931}$ but not women. ${ }^{32}$

We also observed that the associations decreased with increasing age. The observation that risk factors for a disease are weaker for older individuals is not unique for the study of SEP and AF, as the impact of CVD risk factors seems to decrease by age. This is partly explained by the survival effect, which means that those with many risk factors already have experienced an event or died before inclusion. ${ }^{33}$ Furthermore, low SEP is associated with higher mortality and a selection bias in the oldest age may explain the observed association. Hence, there may be a selection bias in the oldest cohort of healthier, more educated and richer individuals.

This study has some advantages. It is a population-based, nationwide cohort study with a large sample size increasing the accuracy of the results and minimising the chance of a type II statistical error. Also, the large number of cases allowed for stratified analyses on age and sex and these analyses suggested that the association between high and low SEP on AF was stronger for the youngest and especially women when evaluated on a multiplicative scale. Additionally, the associations of interest were assessed on both an additive (RD) and multiplicative scale (HRs), which allowed for a more detailed interpretation of the associations as the risk of AF is markedly higher among older individuals. Furthermore, in Denmark, both education and healthcare services are government funded and free for all citizens, and the effect seen is not influenced by unequal access to rather healthcare services or education, which may be the case in, for example, American studies where the healthcare system is primarily privately funded. ${ }^{94}$ However, citizens may not use the access to healthcare to a similar extent across age, sex and socioeconomic groups.

Finally, by increasing the knowledge about SEP and AF, public health initiatives (eg, unsolicited screening of AF, information campaigns or clinical guidelines) may be developed with a specific focus on the most vulnerable groups (young and middleaged citizens with low education and income).

This study also has several limitations. First, it is likely that we underestimate the incidence of $\mathrm{AF}$, as the symptoms of $\mathrm{AF}$ in some cases are weak and not recognised by the patients or health professionals. ${ }^{35}$ Previous studies have shown that patients with low SES were less aware and had less knowledge about $\mathrm{AF}^{8}{ }^{86}$ Hence, there may be a detection bias of AF in individuals with low SEP, which could make the association between low SEP and AF weaker than it actually is. Additionally, some deaths may be attributed to undiagnosed AF, possibly more often in patients with low SEP. ${ }^{37}$ On the other hand, people with low SEP are more frequently hospitalised for any cause than people with high $\mathrm{SEP}^{38}$ which could make the association stronger than it actually is. Second, although the Danish registers are considered to be of high validity, there may be some incomplete data on, for example, education, especially for the oldest age cohort and for immigrants. ${ }^{18}$ We cannot rule out residual confounding, both by factors that are unknown and by factors that we cannot measure. One example is incomplete registration of some diagnoses/conditions in The Danish National Patient Register, for example, obesity. Although we included it as a confounder, we almost certainly underestimate it as very few cases of obesity are actually registered at the hospital. This is also demonstrated in table 1 , which shows a very low prevalence of obesity compared with what we would expect in the Danish population. ${ }^{39}$ Third, although the combined diagnosis of 'AF and/or atrial flutter' is accepted as 'AF', ${ }^{142021}$ we cannot entirely rule out that there may be different mechanisms for the two conditions which may influence the results. Furthermore, although Danish guidelines recommend all patients with $\mathrm{AF}$ to be referred to a cardiologist for an echocardiography or (if indicated) cardioversion, ${ }^{40}$ underestimation of the diagnosis may be present if general practitioners choose to not refer the patient or if the patient is only seen by an out-of-hospital cardiologist.

\section{CONCLUSION}

Low education was associated with an increased risk of being diagnosed with $\mathrm{AF}$ in young individuals but the association decreased with increasing age and was reversed in high and middle-educated women and middle-educated men in the oldest ages. Similar results were seen for income, but the association was weaker. However, since AF is relatively rare in the youngest the absolute risk is low. Although the association is not as strong in older adults, the incidence is much higher which makes the socioeconomic differences in AF incidence a larger public health problem for older than younger individuals, especially for women in their $50 \mathrm{~s}$ and $60 \mathrm{~s}$.

\section{What is already known on this subject}

- Previous studies have shown that low socioeconomic position increases the risk of several cardiovascular diseases. However, results from studies investigating the association with atrial fibrillation have been inconsistent.

\section{What this study adds}

- Low education increases the risk of atrial fibrillation, especially in younger individuals. However, since atrial fibrillation is relatively rare among the youngest, the absolute risk is low. Consequently, the social differences in the incidence of atrial fibrillation are a larger public health burden in older individuals than the youngest.

Contributors EDL, AMJ, SLC, KF, SPJ, MLL, MBJ and SR contributed to the planning, design, analysis and interpretation of data. EDL drafted the manuscript. EDL, AMJ, SLC, KF, SPJ, MLL, MBJ and SR revised the manuscript critically. EDL, AMJ, SLC, KF, SPJ, MLL, MBJ and SR gave approval for the final manuscript.

Funding This study was partly funded by the Karen Elise Jensen Foundation, The Obel Family Foundation and by internal funding.

Disclaimer The funders had no role in the planning, design, analyses of data or writing of the study.

Competing interests None declared.

Patient consent for publication Not required.

Ethics approval Ethical approval is not needed for register-based studies in Denmark.

Provenance and peer review Not commissioned; externally peer reviewed.

Data availability statement No data are available.lt is not possible to share data according to Danish law. Access are only granted to researchers directly responsible for conducting the specific study.

\section{ORCID iD}

Elin Danielsen Lunde http://orcid.org/0000-0002-4058-953X

\section{REFERENCES}

1 Chugh SS, Havmoeller R, Narayanan K, et al. Worldwide epidemiology of atrial fibrillation: a global burden of disease 2010 study. Circulation 2014;129:837-84. 
2 Chen LY, Chung MK, Allen LA, et al. Atrial fibrillation burden: moving beyond atrial fibrillation as a binary entity: a scientific statement from the American heart association. Circulation 2018;137:e623-44

3 Zoni-Berisso M, Lercari F, Carazza T, et al. Epidemiology of atrial fibrillation: European perspective. Clin Epidemiol 2014;6:213

4 Marshall IJ, Wang Y, Crichton S, et al. The effects of socioeconomic status on stroke risk and outcomes. Lancet Neurol 2015;14:1206-18.

5 Kaplan GA, Keil JE. Socioeconomic factors and cardiovascular disease: a review of the literature. Circulation 1993;88:1973-98.

6 Iwasaki Y-ki, Nishida K, Kato T. Atrial fibrillation pathophysiology. Circulation 2011:124:2264-74

7 Czick ME, Shapter CL, Silverman DI. Atrial fibrillation: the science behind its Defiance. Aging Dis 2016;7:635.

8 Lunde ED, Nielsen PB, Riahi S, et al. Associations between socioeconomic status, atrial fibrillation, and outcomes: a systematic review. Expert Rev Cardiovasc Ther 2018;16:857-73.

9 Misialek JR, Rose KM, Everson-Rose SA, et al. Socioeconomic status and the incidence of atrial fibrillation in whites and blacks: the Atherosclerosis risk in communities (ARIC) study. J Am Heart Assoc 2014;3:e001159.

10 Zöller B, Li X, Sundquist J, et al. Neighbourhood deprivation and hospitalization for atrial fibrillation in Sweden. Europace 2013;15:1119-27.

11 Murphy NF, Simpson CR, Jhund PS, et al. A national survey of the prevalence, incidence, primary care burden and treatment of atrial fibrillation in Scotland. Heart 2007:93:606-12.

12 Wasmer K, Eckardt L, Breithardt G. Predisposing factors for atrial fibrillation in the elderly. J Geriatr Cardiol 2017:14:179-84.

13 Shavers VL. Measurement of socioeconomic status in health disparities research. J Natl Med Assoc 2007:99:1013-23.

14 Schmidt M, Schmidt SAJ, Sandegaard JL, et al. The Danish national patient registry: a review of content, data quality, and research potential. Clin Epidemiol 2015;7:449-90.

15 Lynge E, Sandegaard JL, Rebolj M. The Danish national patient register. Scand J Public Health 2011;39(7 Suppl):30-3.

16 Kildemoes HW, Sørensen HT, Hallas J. The Danish national prescription registry. Scand I Public Health 2011;39(7 Suppl):38-41.

17 Baadsgaard M, Quitzau J. Danish registers on personal income and transfer payments Scand J Public Health 2011:39(7 Suppl):103-5.

18 Jensen VM, Rasmussen AW. Danish education registers. Scand J Public Health 2011:39(7 Suppl):91-4.

19 Pedersen CB. The Danish civil registration system. Scand J Public Health 2011;39(7 Suppl):22-5.

20 Lloyd-Jones DM, Wang TJ, Leip EP, et al. Lifetime risk for development of atrial fibrillation: the Framingham heart study. Circulation 2004;110:1042-6.

21 Rix TA, Riahi S, Overvad K, et al. Validity of the diagnoses atrial fibrillation and atrial flutter in a Danish patient registry. Scand Cardiovasc J 2012;46:149-53.

22 The Danish rural development programme 2008-2013. Denmark: Ministry of Food Agriculture and Fisheries; 2012. https://naturerhverv.dk/fileadmin/user_upload/ NaturErhverv/Filer/Tilskud/Projekttilskud/Landdistrikter/LDP_Rev_proposal_Consolid_ 2007-2013f.pdf
23 Andersen PK, Perme MP, Pohar Perme M. Pseudo-observations in survival analysis Stat Methods Med Res 2010;19:71-99.

24 Mortensen LM, Hansen CP, Overvad K, et al. The Pseudo-Observation analysis of TimeTo-Event data. example from the Danish diet, cancer and health cohort illustrating assumptions, model validation and interpretation of results. Epidemiol Method 2018;7:1-15.

25 Christensen AV, Koch MB, Davidsen M, et al. Educational inequality in cardiovascular disease depends on diagnosis: a nationwide register based study from Denmark. Eur $J$ Prev Cardiol 2016;23:826-33.

26 Frewen J, Finucane $\mathrm{C}$, Cronin $\mathrm{H}$, et al. Factors that influence awareness and treatment of atrial fibrillation in older adults. QJM 2013;106:415-24.

27 Mou L, Norby FL, Chen LY. Lifetime risk of atrial fibrillation by race and socioeconomic status. Circulation 2018;11:e006350.

28 Havranek EP, Mujahid MS, Barr DA, et al. Social determinants of risk and outcomes for cardiovascular disease: a scientific statement from the American heart association. Circulation 2015:132:873-98.

29 Fransson El, Stadin M, Nordin M, et al. The association between job strain and atrial fibrillation: results from the Swedish wolf study. Biomed Res Int 2015:2015:1-7.

30 Damaske S, Smyth JM, Zawadzki MJ. Has work replaced home as a Haven? reexamining Arlie Hochschild's time bind proposition with objective stress data. Soc Sci Med 2014;115:130-8.

31 Torén $K$, Schiöler $L$, Söderberg $M$, et al. The association between job strain and atrial fibrillation in Swedish men. Occup Environ Med 2015;72:177-80.

32 Westcott SK, Beach LY, Matsushita F, et al. Relationship Between Psychosocial Stressors and Atrial Fibrillation in Women $>45$ Years of Age. Am J Cardiol 2018; 122:1684-7.

33 Lind L, Sundström J, Ärnlöv J, et al. Impact of aging on the strength of cardiovascular risk factors: a longitudinal study over 40 years. J Am Heart Assoc 2018;7. doi:10.1161/JAHA.117.007061

34 National Research Council and Institute of Medicine. U.S. Health in International Perspective: Shorter Lives, Poorer Health. Washington, DC: The National Academies Press, 2013: 106-7.

35 Chugh SS, Blackshear JL, Shen WK, et al. Epidemiology and natural history of atrial fibrillation: clinical implications. J Am Coll Cardiol 2001;37:371-8.

36 Meschia JF, Merrill P, Soliman EZ, et al. Racial disparities in awareness and treatment of atrial fibrillation: the reasons for geographic and racial differences in stroke (REGARDS) study. Stroke 2010:41:581-7.

37 Kargoli F, Shulman E, Aagaard P, et al. Socioeconomic status as a predictor of mortality in patients admitted with atrial fibrillation. Am J Cardiol 2017;119:1378-81.

38 Taylor CB, Ahn D, Winkleby MA. Neighborhood and individual socioeconomic determinants of hospitalization. Am J Prev Med 2006;31:127-34.

39 OECD obesity update Organisation for Economic Co-operation and Development (OECD); 2017. www.oecd.org/health/obesity-update.htm

40 Brandes A, Jensen HK, Pedersen OD. Atrieflimren OG atrieflagren (English: atrial fibrillation and atrial flutter), 2019. Dansk Cardiol. Selsk. Available: https://www. cardio.dk/af\#152-faktorer-og-tilstande-som-er-associeret-med-atrieflimren [Accessed 4 Aug 2019]. 